\title{
EVALUATION OF QUALITY CONCEPTS INFLUENCING A MANUFACTURING ENVIRONMENT IN SOUTH AFRICA*
}

\author{
P. Erasmus ${ }^{1}$ and C.C. van Waveren ${ }^{2}$ \\ Graduate School of Technology Management \\ University of Pretoria, South Africa \\ ${ }^{2}$ corro@up.ac.za
}

\begin{abstract}
This article evaluates the influence that quality concepts and tools in a manufacturing environment may have on parameters possibly affecting the future design and development of products in the same company. It attempts to establish how quality results can be utilised to determine the level of quality control tools used, such as Quality Function Deployment and Concurrent Engineering, in a company that designs for manufacture. By establishing links from quality results and customer requirements, the research determines what critical quality tools are necessary to determine the capability to manufacture an item without the use of excessive planning resources.
\end{abstract}

\section{OPSOMMING}

Hierdie artikel evalueer die invloed van kwaliteitskonsepte en kwaliteitsgereedskap in 'n vervaardigingsomgewing ten einde die effek daarvan op toekomstige ontwerp en ontwikkeiling te bepaal. Die doel is om kwaliteitsresultate te gebruik om die gebruiksvlak van kwaliteitsbeheergereedskap soos bv "Quality Function Deployment" en "Concurrent Engineering" te bepaal in 'n maatskappy wat 'n ontwerpsfunksie vervul vir vervaardigingsdoeleindes. Deur hierdie verwantskap tussen kwaliteitsresultate en kliëntvereistes te ondersoek, word bepaal welke kritiese gereedskap benodig word om die kapasiteit van vervaardiging van 'n komponent te bepaal sonder die gebruik van 'n uitgebreide beplanningshulpbron.

\footnotetext{
*This paper was presented at the IEEE Africon 2007 Conference in Windhoek, Namibia. The paper is reproduced with kind permission of Africon and IEEE

${ }^{1}$ The author was enrolled for an M Eng (Project Management) degree at the Graduate School of Technology Management, University of Pretoria.
} 


\section{INTRODUCTION}

The notion of 'quality' has been around since the dawn of humanity. The inherent ability of humankind to create, and then to benchmark their creation against that of their neighbour, has been the driving force behind the evolution from primitive humankind to the hyperchange environment in which we currently conduct business. The progression of manufacturing objects from self-sustainable farming and war implements, to objects of need and desire, not only paved the way for the creation and evolution of a bartering/monetary system, but also for conceptualising and establishing quality concepts, parameters, and quality systems.

With quality emerging as a science, the study of the subject, its evolution, and its eventual growth in the manufacturing environment, produced several 'masters of the science', such as W. Edwards Deming, Genichi Taguchi, and J.M. Juran. However, very rarely is the quality control of a final product used when considering the design of the next generation product, thus increasing the possibility of failure and extending the time necessary to get a product from conceptualisation to market. This paper proposes a process to assess the evaluation of the current utilisation of quality tools and their effectiveness, while simultaneously offering recommendations to improve the process.

The objective of the research lies initially in the evaluation of quality and quality-related processes in the manufacturing environment of a fast moving consumer goods (FMCG) company in South Africa. It proposes to evaluate the design-to-manufacturing process from a quality control point of view, through the use of quality tools on finished goods, to determine the optimisation of the process that would ensure not only a better product, but a better process as a whole. The article then evaluates the involvement of other manufacturing entities in South Africa to assess the knowledge of quality and quality related tools in a sample of the South African manufacturing environment, with a view to making recommendations to the quality fraternity of South Africa on topics, means, and processes to market, and to entrench the science of quality in local manufacturing industries.

In order to understand the relevance of quality control to concurrent engineering and quality function deployment, current models in literature have been used to evaluate the concepts. Evaluation of these models clearly indicates that quality control is an integral part of the design regime, linked to the quality function deployment process of concurrent engineering.

Application of the abovementioned models offers the opportunity to establish the degree to which the different tiers in the model are currently implemented internally in a company. Levels such as Computer Aided Design (CAD) can be evaluated using benchmarking of the existing operation against similar operations throughout the rest of the world. Added to that, quality functional deployment in the operation can be evaluated against the rules set out later in this paper. The design method should be interrogated using the inputs from the value analysis, quality evaluation, and design for manufacture/assembly (DFX) process, while the failure mode and effects analysis (FMEA) can assist in solving the current problems experienced on a level (or levels) of the manufacturing entities. Application of this model enables the business unit to ensure that most of the major technical elements of the process are addressed, while the detailed evaluation of the process can be determined using the model by Ainscough et al. [1].

\section{QUALITY IN MANUFACTURING}

According to Gitlow et al, [2], the existence of quality control can be traced back to the likes of tribal chiefs, kings, and pharaohs. An example of a quality issue can be found in the Code of Hammurabi, dating from as early as $2000 \mathrm{BC}$. In order fully to understand the science of quality, it is necessary to understand that quality as a concept has a different meaning for each individual, and thus it is necessary to evaluate this concept as a 
progressive series of meanings or definitions. The Japanese Industrial standard JIS Z 81011981, "Glossary of Terms Used in Quality Control", defines quality control (QC) as a system of techniques for economically producing goods and services that meet customers requirements, and - according to Ozeki and Asaka [3] - one must understand the meaning of quality control to be able to apply it extensively to all management activities. Such an understanding is the task and responsibility not just of a quality control department, but rather of all offices, departments, and employees in the company.

Although the quality control process can be seen as a science, the influences of a quality control process are directly dependent on the individuals who are involved in the establishment of the process, systems, and control measures that ensure that quality is achieved (or not). According to Cottmann [5], engineers resent administration; have a strong desire for freedom in their work; are preoccupied with detail; are technically orientated; are well educated and perfectionists; are logical, take pride in their work, and have great respect for competence; and expect that people will be as predictable as physical laws. Cottman [5] continues with his evaluation of the human influences on quality control by evaluating the factors that motivate individuals to perform to the best of their abilities. He bases his motivational concept on the work that Frederick Herzberg and associates reported in the book, The Motivation to Work. According to this research, motivational factors can be classified in two sets: hygienic, and true motivational. Hygienic factors are those who a few people will be motivated by, but most people will feel dissatisfied if they are not present, while true motivational factors build high level job satisfaction.

In 1924 the mathematician Walter Shewhart introduced statistical quality control as a method for economically controlling quality in mass production environments. Although Shewhart's primary interest was in statistical methods, he was very aware of the principles of management and the behavioral sciences. When evaluating statistical control of processes, the approach in the production and control charts is based on a simple premise: that everything varies according to a predictable pattern. However, a problem is introduced by variation that can have a negative effect on control. Therefore, accurate measurement of each action within the steps of any process becomes a requirement. That requirement is satisfied by the introduction of statistical process control (SPC). When evaluating the capability of a manufacturing process, all sources of variation need to be taken into account. There is a distinct possibility that the process, even when in absolute control, cannot provide an output that is satisfactory to the end user. Unless the process satisfyies the customer's requirements, the process is suspect, and a change should be considered.

Quality function deployment (QFD) is a method (or tool) to ensure the quality of new products, starting from the planning and development stages. According to Galano [4], it enables a company to determine upstream the quality of design needed to satisfy a customer, and then to extract the key points linked to quality assurance. The concept of QFD originated in Japanese culture, which understood that the only way to ensure future growth was to ensure continuous development. From this flowed the need to ensure that whatever was being developed was done in such a way that downstream problems were anticipated and eradicated at the conceptual or design stages. Coupled closely to the process of quality functional deployment is the concept of concurrent engineering (CE). The product development cycle begins with the conception of a need based on market analysis and research and development activities. According to Parsaei and Sullivan [6], it has been recognised that design decisions made early in the product development cycle can have a significant effect on the manufacturability, quality, product cost, product introduction time, and ultimate market success of the product. When using concurrent engineering, the typical goals that should be achieved, according to Kušar [7], are:

- $\quad$ Considerably shorter new product development time

- $\quad$ Reduced new product development costs, and

- $\quad$ Better quality of new products regarding the customer needs 
When evaluating concurrent engineering, many terms have been used to describe similar approaches, including simultaneous engineering, life-cycle engineering, design fusion, parallel engineering, concurrent design, and design fusion. Some countries have labeled the process Design for Manufacture (DFM). Others have linked the concept to processorientated technological terms such as Design for Manufacturability (DFM), design for producibility, design for reliability, design for serviceability, and so on, until Gatenby and Foo coined the term 'Design for X' (DFX) where the X stands for all of the above '-ilities'. Starbek and Grum [8] proposed to implement concurrent engineering into small companies, but found that one such company did not possess all the tools required for concurrent engineering support; so the company management decided that the established teams should first implement quality function deployment (QFD).

From a management perspective there is a need to recognise the pivotal role that design quality plays in the overall spectrum of quality performance. Firms need to recognise the influential role of design quality on other measures of quality performance, such as conformance quality and external quality-in-use. Designing quality into a product will reduce costs, improve quality in the marketplace, and improve competitiveness. Thus, while conformance quality is likely to be an 'order-qualifier', design quality has more of the hallmarks of an 'order-winner'.

\section{RESEARCH DESIGN AND METHODOLOGY}

The strategic importance of the research is closely linked to the work of Fynes and Búrca [9] in Ireland and Starbek and Grum [8] in Slovenia, who set out to establish the level of quality knowledge, and specifically concepts such as Quality Function Deployment and Concurrent Engineering, in their respective countries. This current research is seen to be important because of the information it hopes to establish through a case study in a South African environment. The methodology will be to evaluate the current process of design to manufacture on the internal processes and quality derivatives internal to the company. Using manufactured components, the process from concept to final manufacturing will be followed, and the discussed quality tools will be used to determine the accuracy and usability of the component. Following the internal evaluation of the quality processes and results, the research will further focus on the knowledge and implementation of these processes in other manufacturing environments in South Africa. The research will try to establish the level of knowledge of quality and quality-related topics in these environments by means of a quality-related questionnaire.

The data were acquired in different ways for different aspects of the research. Initially, data for the evaluation of the internal quality processes were generated by initiating a manufacturing run of one of the components manufactured by the company for the purpose of evaluating the variable and attributive quality systems that would ensure the integrity of the process. Using pre-determined information, the manufacturing run was especially executed on a component known for being problematic and difficult to manufacture. The reason for this choice was to ensure that, should positive results be achieved in the evaluation of this process, further roll-out to less difficult components manufactured by the company could easily be entrusted to its quality assurance staff in order to ensure continuous improvement of its other manufacturing processes. Secondly, the manufacturing of a more difficult part would practically ensure a set of results that would most definitely indicate room for improvement. In order to ensure some level of reliability and repeatability, and to remove at least one of the variables from the equation, the measurements were performed by one individual using one calibrated instrument. This not only ensured repeatability, but the fact that the person is involved in the measurement of the components practically every day would also ensure that the reliability of the measurement results was assured. Results of the measurements were recorded in the order of samples taken (i.e. sample 1 from first set of samples rendered result 1). Although the logic at the time was to determine if a pattern existed between the taking of the sample and measurement, results soon indicated that this route was unnecessary, as the randomness of the results indicated that there was no discernible pattern. 
A second set of data was generated from questionnaires sent to companies that supply components to the company in question (CBI Electric) in order to determine their level of knowledge of quality and quality-related topics and tools among their quality personnel. The questionnaire was drawn up to determine, first, the current supplier base with regards to ISO certification, as well as the level of knowledge with regard to ISO certification. The questionnaire then tries to determine the level of quality personnel in the respective organisations and the effectiveness of their efforts. Following from this, the questionnaire determines the level of knowledge that companies have of quality tools, and how actively these tools are being utilised and implemented in the respective companies to ensure that good quality components are manufactured. Finally, the questionnaire touches a little on in-house design before it tries to determine how companies view their ability to perform and grow in the current changing South African and international environments. Finally, the questionnaire asks whether South African manufacturing quality is "as good as (or better than) the rest of the world?" with interesting results. A return rate of about $30 \%$ of the original questionnaires was achieved, but only 35 of the participating companies' results met the original criteria (South African, Manufacturing) set out by the author. These were then processed for conclusive results.

\section{RESULTS}

\section{A. Internal company results}

Evaluation of the measurement processes to determine final product quality, and evaluate it against process capability and design intent, was performed using known quality tools such as mathematical modeling and statistical process control. The typical initial evaluation from the data is the X-Bar and Range (R) Charts. Following the X-Bar Chart, the Range chart can be plotted to monitor the variability of the process between observations in the subgroup over time. The benefit of the range charts is to demonstrate out of control points effectively. If there are any, then these special causes must be eliminated from future calculations, as they will skew information on a process, possibly leading to incorrect results and conclusions. Brainstorming and designed experiments will assist in finding those process elements that contribute to sporadic changes in variation, and that may be eliminated from future operations, data, and calculations.

Evaluation of the internal manufacturing process using quality tools such as statistical process control, X-Bar and R-Charts, and capability analysis, indicates that the current manufacturing process, measured against original design intent, is only somewhat capable in some of the features measured. Figure 1 indicates the results of the capability study, rendering the process capability of manufacturing the inside width of the component Cpk = 0.51 , where a value of 1.33 is typically accepted for an 'In control' process.

However, the process in its entirety could not be deemed capable of manufacturing the component statistically correctly to the point where scrap and reject rates are minimised for the benefit of the company. It needs to be stressed that the capability studies were performed on individual features of the same components; and the mere fact that one or two of the features indicated some capability does not render the process 'half right'. If one feature of a component is incorrect, the component may not fulfill the end need, and therefore the component should be deemed to be incorrect. A similar approach should be taken with capability. The actualisation of the concurrent engineering process may even be initiated as a process of evaluating the different areas of influence, as described in the model proposed by Ainscough et al. [1]. The model is broken down into the departmental building blocks normally associated with concurrent engineering. Evaluating the results from the quality evaluation, and superimposing the Ainscough model on to the results, raises several questions, such as the need to review the development of the components with checklists. Defined levels of detail are another area where the current process may be lacking, whereas concurrency built into the process could be one of the most difficult areas to attain. Similarly, the concept of teamwork may sound systematic, but the current process of project management in the company should ideally stimulate the subject, rather 
than the old approach of sequential engineering, where the final quality of a product has no influence on a product or component before it is designed. The concept of multifunctional teams has been established for some time, and the concept of small, mobile task teams (tiger-teams) has also been used successfully; but the implementation of such teams tends to be rare in current design and manufacturing environments. Similarly, the concepts of functional skills (e.g. a metallurgist as part of the design team) and empowered decisionmaking are also areas which may or may not always be used to the full.

\section{INSIDE WIDTH}

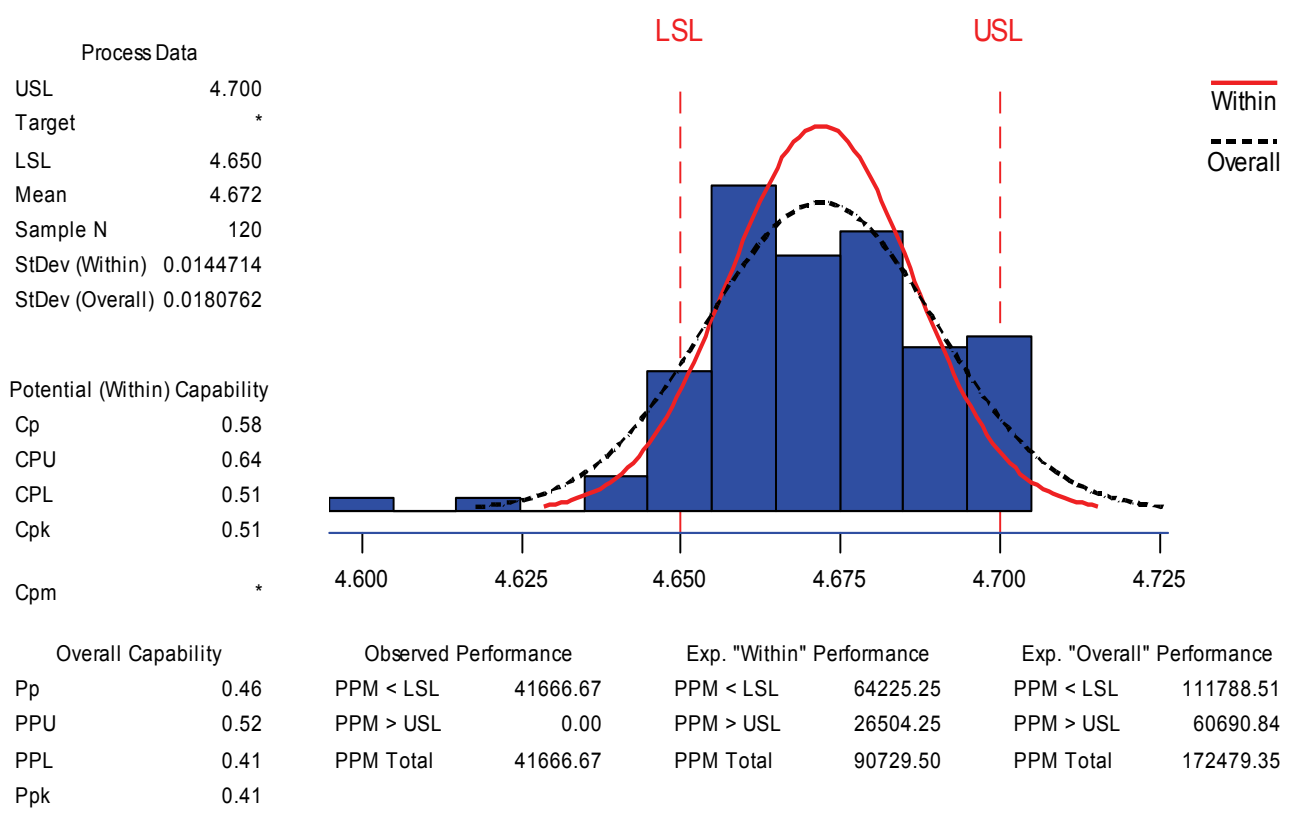

Figure 1: Results of capability evaluation of inside width

\section{B. External company questionnaires results}

Results from the external questionnaire were obtained by evaluating the data received from the different participants. The individuals participating in the process were not identified, and may or may not have been from the quality fraternity; however, all were directly involved in the direct supply chain.

The subject of the first four questions deals with the knowledge and implementation of ISO as a governing quality system. The purpose of the questions was to determine the level of knowledge and acceptance of ISO as an international standard. This knowledge and acceptance indicates, by implication, the willingness of South African manufacturing companies to participate on a globally accepted scale. Figures 2 and 3 indicate, first, the level of knowledge, and second, the level of acceptance and implementation of ISO 9001. Although the majority of the participants indicated a familiarity with the system, it is unclear whether the two participants who indicated non-familiarity were completely unfamiliar with the system, or whether their indication is that they have some knowledge of the system's existence but are not completely familiar with the entire content of the system. 
Are you Familiar with ISO 9001?

Responses

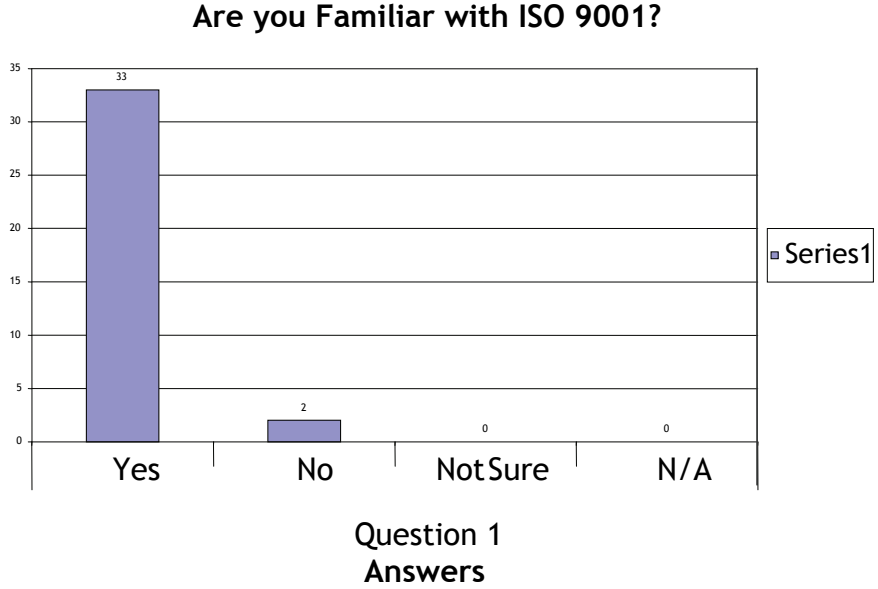

Figure 2: Knowledge of ISO 9001

Further information indicates that 21 of the 35 participants are indeed ISO-certified, indicating that the system is widely accepted in South Africa, but that improvements are indeed necessary. The data suggests that most of these companies have been certified for longer than five years.

The results of the external questionnaire indicated several areas where conclusions could be made about the general approach to quality and quality-related tools in the South African manufacturing environment. On evaluation of the understanding and implementation of the ISO quality systems, it can be concluded that the general knowledge of ISO in the South African manufacturing environment is very good, but that the actual implementation of the system is not necessarily achieved. Only about $60 \%$ of the companies polled were ISO-certified, though most of these were certified for periods longer than five years. When non-certified companies were asked if they planned to certify in future, the majority answered 'yes'. From these answers it can be concluded that South African companies understand the importance of ISO certification as an order qualifier for entrance into the international supplier market. Only two of the participants (roughly $5 \%$ ) indicated that they were not interested in certification.

Is your company ISO certified?

\section{Responses}

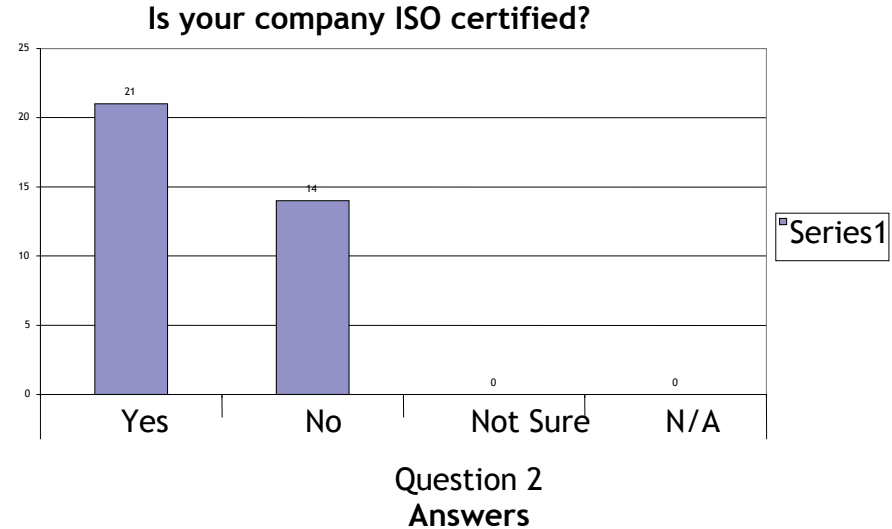

Figure 3: ISO 9001 Certification by participants

Evaluation of quality as a science, and the implementation of quality as a tool in manufacturing environments, indicated that most of the companies employed some individuals with the sole responsibility of looking after quality. These ranged between zero and $30 \%$ of the companies' employees; those that indicated $0 \%$ qualified their answers by 
indicating that everybody in their establishment was responsible for quality. Evaluation of the quality statistics indicated that an average of $2 \%$ of manufactured components are rejected in-house by the manufacturing entities, while about $1.5 \%$ of defective components are missed and returned by outside customers. This indicates an overall reject rate of about $3.5 \%$, clearly indicating room for improvement. What is encouraging, however, is that the majority of these participants have an internal corrective action system that is used to address customer complaints formally. These complaints are also handled high up in the hierarchy of the organisation (quality managers, etc.), again indicating that the concept of quality is regarded highly in the South African manufacturing environment.

In spite of the efforts of the companies to ensure the quality of their products, the general knowledge of quality tools within these companies is poor. Less than half of the companies employ statistical process control in their environments, as shown by Figure 4. Coupled to this is the fact that $34 \%$ of the participants are not familiar with Failure Mode and Effects Analysis, and even more of the companies (55\%) have never heard of Regression Analysis. These are standard tools in the science of quality, and the mere fact that the existence of these tools is unknown in these manufacturing environments is somewhat alarming. It can therefore be concluded that in general, quality tools are unknown to a large contingent of South African manufacturing companies.

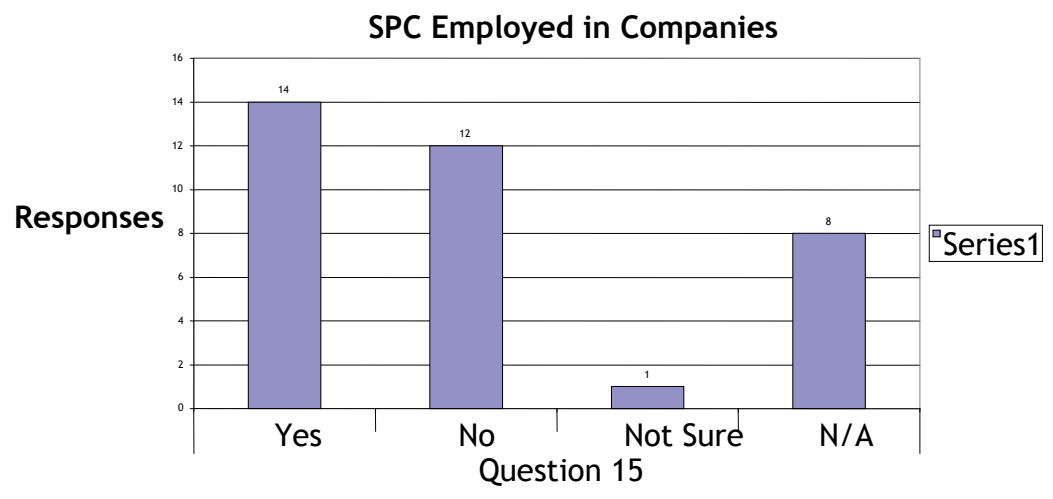

Answers

Figure 4: Evaluation of the use of SPC tools

Evaluation of the measurement equipment used in the control of quality indicated that calibration of equipment is a process most of the companies undertake. The sequipment is mostly calibrated both internally and externally, which indicates that thought goes into these decisions. A large number of the companies in question use external calibration, while about $10 \%$ of the participants only calibrate in-house. The conclusion that can be made that South African manufacturing companies understand the importance of ensuring the integrity of their measurement equipment, and are taking active steps to ensure both internal and external calibration of their equipment. However, reliability and repeatability studies are not generally performed on test equipment. The research indicated that only one quarter of companies have ever carried out such studies on their equipment, and it is clear that there is definite room for improvement here.

The implementation of concurrent engineering is clearly an area where South African manufacturing companies can improve. The concept of concurrent engineering is relevant not only to manufacturing entities but also to all businesses where cross-departmental interactions occur. The whole concept of concurrent engineering is based on the fact that sequential processes are performed in parallel rather than in series. Figure 5 shows that less than $10 \%$ of participants in the questionnaire employ concurrent engineering in their manufacturing plants. 
Exploring this further to determine the capability of the manufacturing processes, only $40 \%$ of these participants have ever performed a capability study. From the evidence it is clear that there is a serious lack of implementation of quality tools in the South African manufacturing community; and this needs to be addressed as a matter of urgency.

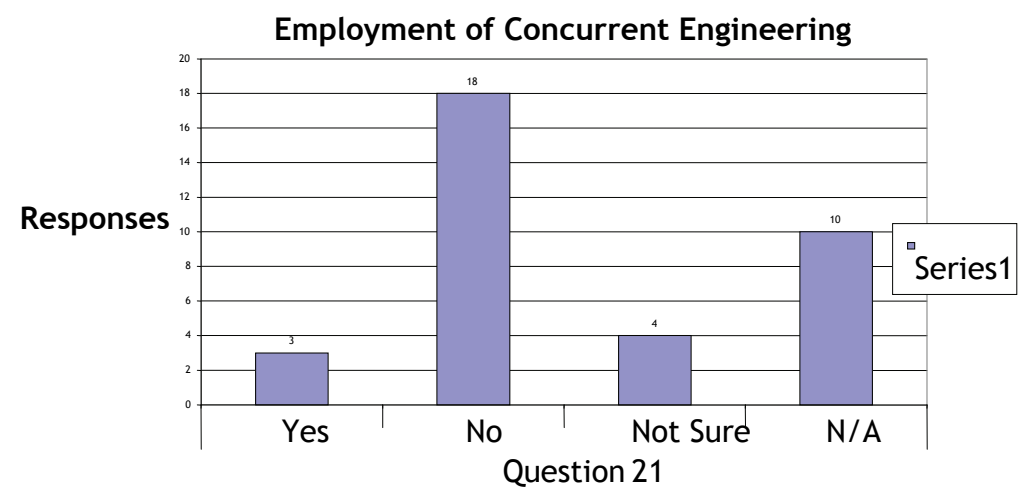

Answers

Figure 5: Indication of the use of concurrent engineering

Participating companies that did in-house design were less than half of the sampled population. It appears that most of the companies manufacture on demand, supplying a service to other designing entities to outsourced specifications. Of the sampled participants, only one quarter had any inclination to use design methodologies for manufacturing, which also suggests that there is definitely room for improvement in this area. The knowledge of design methodologies will benefit not only those companies that have in-house design facilities, but also those that manufacture. This is due to the fact that these companies may have a better insight into the manufacturing process, and will be able to make recommendations about obvious design improvements, cost reductions, or ease of manufacture processing.

Considering areas of improvement in the implementation of certification, quality tools, and concurrent engineering, the general view of South African manufacturing companies is that there is a room for improvement in their operations in the South African and international environments. The outlook of the participating companies indicated that over $90 \%$ of them believed that they could grow their business on local soil (Figure 6), while over $80 \%$ believed that they had the ability to expand into international markets (Figure 7).

Similarly, Figure 8 indicates that over $70 \%$ of the companies that took part in the questionnaire believed that the manufacturing quality of South African companies is comparable to (or better than) what is available in the international markets.

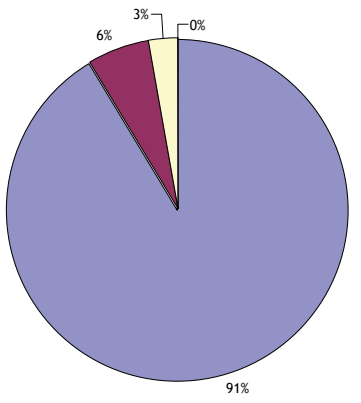




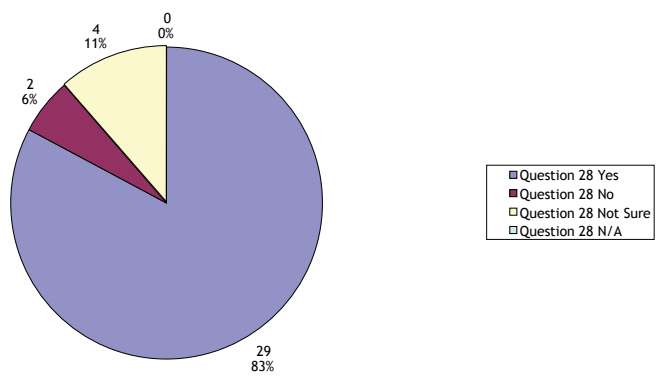

Figure 7: Belief in growth internationally

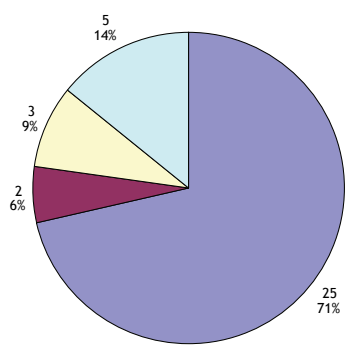

Figure 8: South African quality - Comparable to international standards?

It appears from these results that there is definitely capacity for South African manufactured components in the international market, but that the South African manufacturing community will have to employ several measures to ensure that the quality of components generated in their factories not only satisfies a part of the international market (such as Africa), but that they can be used by the broader spectrum of users in first world countries as well. In order to achieve this, these companies will have to invest heavily in increasing their overall product value; and the only way to ensure their competiveness against emerging markets such as Brazil, India, and China, would be to focus on time-to-market, price, and exceedingly good quality to tight tolerance. The only way to achieve such growth would be to implement the processes discussed in this article, such as concurrent engineering, which acts as a management tool that decrease time-to-market, ensure manufacturability and proper assembly, and also address the quality issues that arise. It can be concluded, further, that in order to ensure the sustainability of these processes, it is important to get buy-in from top management in order to ensure a top-down approach to the issues. The implementation of processes such as Statistical Process Control, Quality Function Deployment, Concurrent Engineering, and Design for X (to name but a few) will only succeed by using the necessary knowledge and resources linked to the process. The planning of the implementation process of these components will be extremely delicate, and it will be necessary to apply knowledge and energy to the process. The payoff, however, will be significant and continuous - as long as the companies can continue growing their technological, quality, and process advantage over other manufacturing entities worldwide. 


\section{CONCLUSION}

Following the formal strategic initiation of the process in the company, the steps of concurrent engineering can be benchmarked against similar manufacturing companies in the world, in order to determine where resources and effort should be concentrated and implemented. The author believes that the company would benefit most from focusing its efforts on these elements: 'Formal Process', 'Teamwork' and 'Information Technology', as found in the Ainscough model. The formal process would typically benefit the time-tomarket process, while teamwork and information technology would also benefit the timeto-market process along with quality and cost.

After evaluating the current processes against those of similar entities, it would be wise to evaluate current drivers, such as time-to-market, quality, and cost, and to propose new strategic goals for these drivers within a five year plan. The plan will then have to be refined into annual and eventually quarterly achievable goals in order to ensure the success of the process. It is important to understand at this point that the changes proposed by the five year plan would be radical, but so would be the results. The proposed process would not only affect current manufacturing operations, but also completely influence the input of the marketing and sales division, as well as the human and technical resources areas.

It is therefore clear that the recommendations proposed to the company indicate an extreme re-engineering of the current processes and technologies in order to make use of available (but inadequately used) tools and technologies. This would benefit the company by dramatically improving the time-to-market of new developments, cost of projects, processes, and operations, as well as improving the quality of the final product. The recommendations are made in order to ensure the company's continuous growth, combined with continuous improvement of the operation to ensure sustainable development.

From the evidence, it seems clear that there are several areas where the results, as presented in this article, can be broken down into further fields of study that are relevant to the South African manufacturing market and its role players. First, it is necessary to know that the participants in this study came from all types of manufacturing areas. There is a need to widen the study to distinguish between turning plants, electronic component manufacturers, raw material manufacturers, fastener manufacturers, plastic component suppliers, and so on. This information could help the country's quality contingent to focus their efforts, while the companies themselves could benchmark their efforts against other companies in their realm of operation. A second area of improvement on the current research would be to ensure that all the information is supplied by the relevant high level management of each organization, as some of the participants in this study may not have had all the information on their companies' strategic direction. This would not only ensure the relevance of the information, but also enable the researcher to gauge the strategic direction of the companies in the future implementation of quality tools and operations, and to have more insight into the current effectiveness of operations. It is further recommended that this research be amplified to include more respondents from different areas of the country. The research should then aim to establish whether the implementation of quality as a manufacturing tool is more prevalent in some areas than in others, and if so, what impact this might have had on these results.

It is a well known fact that the motor industry in South Africa has some of the strictest and most compliant quality processes in the country. This has resulted in a range of suppliers that manufacture towards motor industry standards and control their quality to specifications such as VDA6.1 and TS 16949. The motor industry's control over their manufacturing suppliers has produced a set of suppliers who have developed with the growing motor industry, and who are currently protecting their territory fiercely from current competitors and new entrants into 'their' markets. This has had two effects. First, it has created companies that are superior in process and quality, with scope for increased operation in relation to non-motor industry customers. Second, it had created a corps of well-trained, experienced quality individuals who eventually leave the industry to practise 
their trade elsewhere, thereby benefiting the rest of the manufacturing industry in South Africa.

Building on the results of this paper, together with the facts mentioned above, continuing research could determine the gap (through gap analysis) between the knowledge and implementation of quality and quality tools of motor industry suppliers and non-motor industry suppliers, to establish exactly how much the country has benefited from the efforts of the motor industry, and whether their efforts should be expanded to the rest of South Africa's manufacturing industries.

In conclusion, this article has sought to evaluate the level of knowledge, acceptance, and implementation of quality tools in South Africa's manufacturing environments, by probing current operations in a manufacturing environment. The research was then expanded to manufacturing companies currently involved in the supply of components to the company that was studied, and the results were collated so that the similarities and differences between the current operation and its supply could be set out. Evaluation of the processes indicated that the evaluated company has indeed progressed significantly in relation to its suppliers, and recommendations were made to improve further the operation, stature, quality, and involved costs of operations. The author made several recommendations to the polled South African companies to ensure future compliance with acceptance levels. Recommendations were also made to develop the research so that it distinguishes between companies in relation to type of operation, product, and geographical position (to name a few). The author believes that there is still a lot of work to be done in terms of quality in South African manufacturing companies. It is clear, however, that the current favorable political and economic climate in the country can ensure continued growth and improvement. South African manufacturing companies have a lot of skills, which could ensure their position as a top manufacturing entity in the world - provided that these enterprises develop their natural potential and extend their natural resources. The future of South African manufacturing industries appears bright, provided that they embrace the reality of hyper-change and develop into a major contributor in manufacturing.

\section{REFERENCES}

[1] Ainscough, M., Neailey, K. \& Tennant, C. 2003. A self-assessment tool for implementing concurrent engineering through change management, International Journal of Project Management, 21(6), pp. 425-431.

[2] Gitlow, H., Oppenheim, A. \& Oppenheim, R. 1995. Quality management: Tools and methods for improvement, $2^{\text {nd }}$ edition. Illinois: IRWIN.

[3] Ozeki, K. \& Asaka, T. 1990. Handbook of quality tools: The Japanese approach. Cambridge: Productivity Press.

[4] Galgano, A. 1994. Companywide quality management. Portland: Productivity Press.

[5] Cottman, R.J. 1993. Total engineering quality management. Milwaukee: ASQC Quality Press.

[6] Parsaei, H.R. \& Sullivan, W.G. 1993. Concurrent engineering: Contemporary issues and modern design tools. London: Chapman \& Hall.

[7] Kušar, J., Duhovnik, J., Grum, J. \& Starbek, M. 2004. How to reduce new product development time, Robotics and Computer-Integrated Manufacturing, 20(1), pp. 1-15.

[8] Starbek, M. \& Grum, J. 2002. Concurrent engineering in small companies, International Journal of Machine Tools and Manufacture, 42(3), pp. 417-426. 
[9] Fynes, B. \& De Búrca, S. 2005. The effects of design quality on quality performance, International Journal of Production Economics, 96(1), pp. 1-14. 